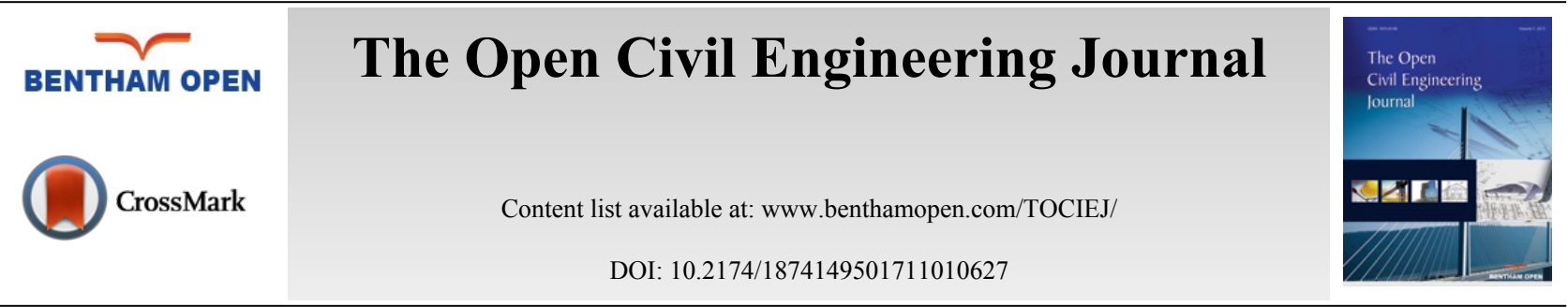

RESEARCH ARTICLE

\title{
Vibration Safety Criteria for Surficial Rock Mass of Open Pit Slope Affected by Underground Mining Blasting Operations
}

\author{
Nan Jiang, Chang Xiong, Chuanbo Zhou*, Xuedong Luo, Shiwei Lu and Zhen Zhang \\ Faculty of Engineering, China University of Geosciences, Wuhan 430074, P.R. China \\ China International Water \& Electric CORP., Beijing 100011, China
}

Received: February 03, 2017

Revised: March 21, 2017

Accepted: June 14, 2017

\begin{abstract}
:
Introduction:

Blasting vibration velocity is an important index to evaluate the stability of mine slopes under blasting operations.

\section{Objective:}

In order to determine the blasting vibration safety criteria for slope rock mass scientifically and reasonably, the influence of stress waves on surficial rock mass of mine slopes was analyzed when stress waves propagate to the slope surface, and mathematical models for blasting vibration safety criteria are proposed based on the ultimate tensile stress criterion, the ultimate shear stress criterion and the Mohr-Coulomb criterion.
\end{abstract}

\section{Results and Conclusion:}

Combined with the field blasting operations during the open-pit to underground mining in Daye iron mine, the blasting vibration safety criteria is calculated. It is obtained that the blasting vibration safety criteria for the north slope and the south slope are $11.08 \mathrm{~cm} / \mathrm{s}$ and $10.20 \mathrm{~cm} / \mathrm{s}$ respectively. The results agree well with the Safety Regulations for Blasting in China and provide a reference to determine blasting vibration safety criteria for other similar projects.

Keywords: Open pit to underground, Blasting vibration, Safety criteria, Rock mass, Mining slope, Surficial rock mass.

\section{INTRODUCTION}

In open-pit to underground mines, partial collapse of surficial rock mass always occurs because the open-pit slopes are subjected to underground blasting mining operations [1], which trigger a serious threat to the workers and equipment. In order to ensure the safe production, it is the key technical problem to determine the blasting vibration safety criteria for slope rock mass scientifically and reasonably and to control blasting vibration effects.

The influence of blasting vibration on slope rock mass has been extensively studied. But most of these studies focused on the overall slope instability [2 - 5], and studies about the blasting-vibration-induced partial collapse of surficial slope rocks are rarely found. Kesimal et al. [6] studied the influence of blasting vibrations on slope instability at a limestone quarry by analyzing the blast-induced accelerations. Yang et al. [7] analyzed dynamic stability of open pit slope under blast loading based on time-history analysis and the software FLAC. Yan et al. [8] analyzed the variation of slope stability factors under blast loading by using the software GEO-SLOPE. The existing results show that numerical simulation is the main approach adopted to analyze the slope stability under blast loading [9 - 11]. Because of the complex action mechanism of blasts, the relevant theory study is relatively less.

\footnotetext{
* Address correspondence to this author at the Faculty of Engineering, China University of Geosciences, 388, Lumo R., Wuhan City, P.R. China; Tel: +86-18164055091; E-mail: happyjohn@foxmail.com
} 
In this paper, the surficial slope rock mass subjected blasting vibration in open-pit to underground mines is taken as research object. The mathematical models for blasting vibration safety criteria are proposed based on the ultimate tensile stress criterion, ultimate shear stress criterion and Mohr-Coulomb criterion. The value of blasting vibration safety criteria is calculated in case study and the results are proven to be reliable.

\section{METHODS}

\subsection{Mathematical Models for Blasting Vibration Safety Criteria}

When blasting stress waves propagate to the slope surface, the reflection-induced tensile stress will loose the surficial slope rock mass and result in some geological hazards, like partial collapse and rockfalls, which will threaten the whole projects [12]. Blasting stress waves can be divided into two categories according to the propagating paths: the stress waves propagating through the interior of media are known as body waves; the stress waves propagating across the surface are known as surface waves. Body waves can be divided into P-waves and S-waves.

According to the field conditions, blasting operations are always right below the toe of open-pit slopes. Blasting stress waves propagate through the interior of slopes to the surface and top of slopes. So only the influence of body waves (P-waves and $\mathrm{S}$-waves) on the failure of slope rocks is studied.

Under blasting vibrations, particles within a certain range of the explosive source are disturbed and vibrations propagate from the explosive source in all directions. When blasting stress waves are incident at the free surface of slopes, reflection and refraction will be caused.

\subsubsection{Reflection of P-waves at the Free Surface}

In stress wave theory, no transmission would be excited when a plane stress wave is incident on a free surface [13]. In this paper, we assumed that the blasting stress wave is a plane stress. In order to study the reflection of a blasting stress wave on a free surface, a coordinate system $O x_{1} x_{2}$ is set up, and the plane $x_{1}=0$ is defined to be the free surface. The slope rock mass is located in the $x_{1}>0$ region, and the $x_{1}<0$ region represents the air. Suppose a blasting stress wave is a plane harmonic P-wave, and $\alpha_{1}$ is defined as the incident angle, $\frac{\omega}{2 \pi}$ as the frequency, as shown in Fig. (1). The displacement $\Phi_{1}$ orthogonal to the wave front is given as follows:

$$
\Phi_{1}=A_{1} \sin \left(\omega t+f_{1} x_{1}+g_{1} x_{2}\right)
$$

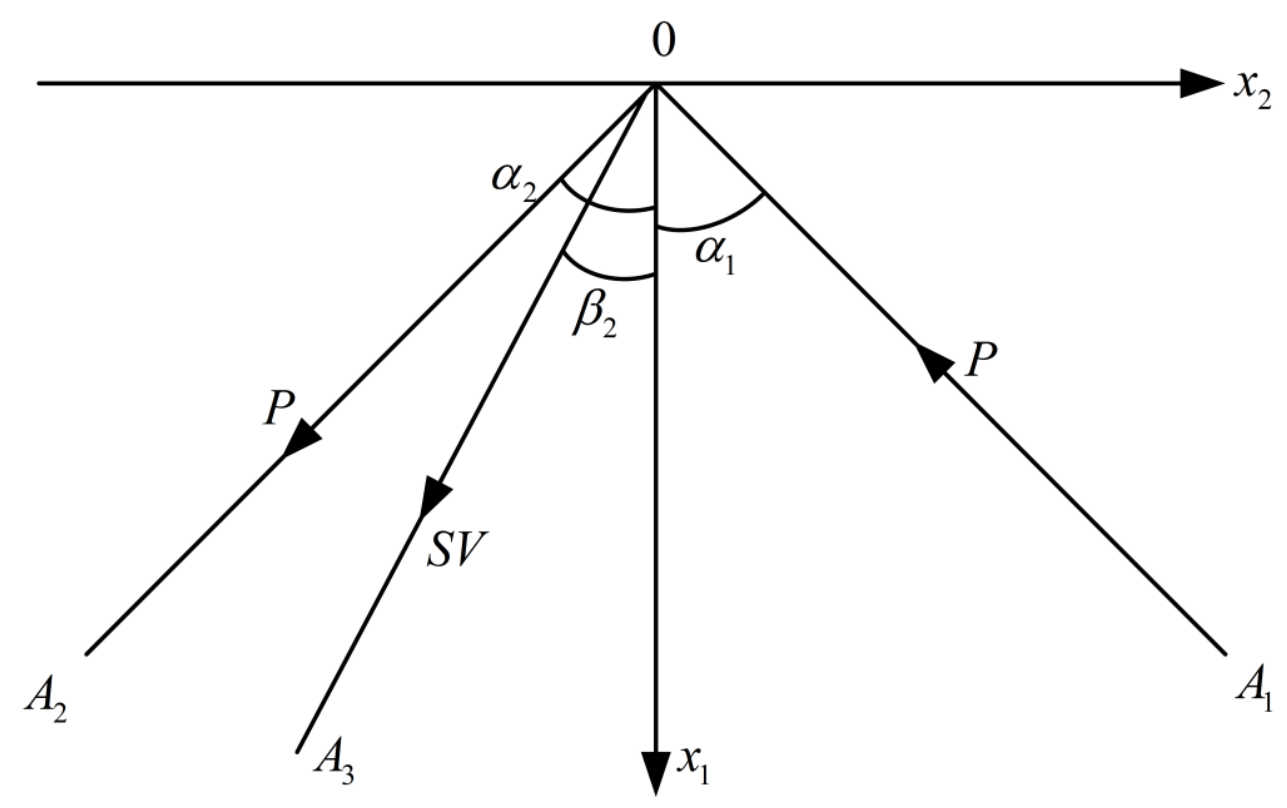

Fig. (1). Reflection of P-waves at the free surface. 
where $A_{1}$ is wave amplitude, $f_{1}=\frac{\omega \cos \alpha_{1}}{C_{p}}, g_{1}=\frac{\omega \sin \alpha_{1}}{C_{p}}, C_{p}$ is the wave speed of P-waves.

$u_{1}$ and $v_{1}$ are the displacements in the directions of $x_{1}$ and $x_{2}$, given by:

$$
\left\{\begin{array}{l}
u_{1}=\Phi_{1} \cos \alpha_{1} \\
v_{1}=\Phi_{1} \sin \alpha_{1}
\end{array}\right.
$$

Let $\alpha_{2}$ be the reflection angle of the reflected P-wave, its displacement orthogonal to the wave front is given by:

$$
\Phi_{2}=A_{2} \sin \left(\omega t-f_{2} x_{1}+g_{2} x_{2}+\delta_{1}\right)
$$

where $A_{2}$ is wave amplitude, $f_{2}=\frac{\omega \cos \alpha_{2}}{C_{p}}, g_{2}=\frac{\omega \sin \alpha_{2}}{C_{p}} \delta_{1}$ is a constant and means the phase change. $u_{2}$ and $v_{2}$ are
ven by: given by:

$$
\left\{\begin{array}{c}
u_{2}=-\Phi_{2} \cos \alpha_{2} \\
v_{2}=\Phi_{2} \sin \alpha_{2}
\end{array}\right.
$$

At the free surface $\left(x_{1}=0\right)$, the normal stress $\sigma_{11}$ and the tangential stress $\sigma_{12}$ both are zero. Let $u$ and $v$ be the total displacement made up from the incident and reflected P-waves. According to the Hooke's law, the components of stress tensor are obtained as:

$$
\begin{aligned}
& \sigma_{11}=\lambda\left(\frac{\partial u}{\partial x_{1}}+\frac{\partial v}{\partial x_{2}}\right)+2 \mu \frac{\partial u}{\partial x_{1}} \\
& \sigma_{12}=\mu\left(\frac{\partial v}{\partial x_{1}}+\frac{\partial u}{\partial x_{2}}\right)
\end{aligned}
$$

where $\lambda$ and $\mu$ are the Lame constants.

Substituting from (1) and (3), equation (5) becomes:

$$
\left\{\begin{array}{c}
A_{1}\left(\lambda+2 \mu \cos ^{2} \alpha_{1}\right) \cos \left(p t+g_{1} x_{2}\right)+A_{2}\left(\lambda+2 \mu \cos ^{2} \alpha_{2}\right) \cos \left(p t+g_{2} x_{2}+\delta_{1}\right)=0 \\
A_{1} \sin 2 \alpha_{1} \cos \left(p t+g_{1} x_{2}\right)-A_{2} \sin 2 \alpha_{2} \cos \left(p t+g_{2} x_{2}+\delta_{1}\right)=0
\end{array}\right.
$$

For all $\left(x_{2}, t\right)$, the two parts of equation (5) cannot be satisfied simultaneously. If the first part is satisfied, $\mathrm{g}_{1}=\mathrm{g}_{2}, \delta_{1}$ $=0$ and $A_{1}=-A_{2}$. But the latter part cannot be satisfied. So there must be a reflected S-wave other than a reflected a Pwave to make the both parts of equation (5) satisfied.

Let $\beta_{2}$ be the reflection angle of the reflected S-wave, its displacement orthogonal to the wave front is given by:

$$
\Phi_{3}=A_{3} \sin \left(\omega t-f_{3} x_{1}+g_{3} x_{2}+\delta_{2}\right)
$$

where $C_{s}$ is the wave speed of S-waves, $A_{3}$ is wave amplitude, $f_{3}=\frac{\omega \cos \beta_{2}}{C_{s}}, g_{1}=\frac{\omega \sin \beta_{2}}{C_{s}}, \delta_{2}$ is a constant for phase change. Because the oscillations of an S-wave occur perpendicular to the direction of energy transfer and it is supposed that the movement only occurs in the same plane, the oscillations lie in the $O x_{1} x_{2}$ plane, known as a SV-wave. Its displacements are given by:

$$
\left\{\begin{array}{l}
u_{3}=\Phi_{3} \cos \beta_{2} \\
v_{3}=\Phi_{3} \sin \beta_{2}
\end{array}\right.
$$


Let $u=u_{1}+u_{2}+u_{3}$ and $v=v_{1}+v_{2}+v_{3}$, the boundary condition of $\sigma_{12}=0$ on $x_{1}=0$ can be written as:

$$
\begin{aligned}
& \frac{A_{1}}{C_{p}} \omega \sin 2 \alpha_{1} \cos \left(\omega t+g_{1} x_{2}\right)-\frac{A_{2}}{C_{p}} \omega \sin 2 \alpha_{2} \cos \left(\omega t+g_{2} x_{2}+\delta_{1}\right) \\
& -\frac{A_{3}}{C_{s}} \omega \sin 2 \beta_{2} \cos \left(\omega t+g_{3} x_{2}+\delta_{2}\right)=0
\end{aligned}
$$

If equation (3) is satisfied for all $\left(x_{2}, t\right)$, there must be $\mathrm{g}_{1}=\mathrm{g}_{2}=\mathrm{g}_{3}$, as follows:

$$
\frac{\sin \alpha_{1}}{C_{p}}=\frac{\sin \alpha_{2}}{C_{p}}=\frac{\sin \beta_{2}}{C_{s}}
$$

So,

$$
\alpha_{1}=\alpha_{2}, \frac{\sin \alpha_{1}}{\sin \beta_{2}}=\frac{C_{p}}{C_{s}}
$$

The reflection angle of reflected P-wave equals to the incident angle and the ratio of the sine of the reflection angle of reflected S-wave to the sine of the incident angle equals to the ratio of the S-wave's speed to the P-wave's speed. Because $C_{p}>C_{s}$, the reflection angle $\beta_{2}$ greater than the incident angle $\alpha_{1}$. The values of $\delta_{1}$ and $\delta_{2}$ can only be zero or $\pi$. Now let $\delta_{1}=\delta_{2}=0$, the amplitudes satisfy:

$$
2\left(A_{1}-A_{2}\right) \cos \alpha_{1} \sin \beta_{2}-A_{3} \cos 2 \beta_{2}=0
$$

Similarly, let $\mathrm{g}_{1}=\mathrm{g}_{2}=\mathrm{g}_{3}$ and $\delta_{1}=\delta_{2}=0$ in the boundary condition of $\sigma_{11}=0$ at $x_{1}=0$. Then the amplitudes satisfy:

$$
\left(A_{1}+A_{2}\right) \cos 2 \beta_{2} \sin \alpha_{1}-A_{3} \sin \beta_{2} \sin 2 \beta_{2}=0
$$

Equations (12) and (13) form a linear system of equations. For a given incident P-wave, the amplitudes of reflected waves $A_{2}$ and $A_{3}$ can be obtained as follows,

$$
\left\{\begin{array}{l}
\frac{A_{2}}{A_{1}}=\frac{\sin 2 \alpha_{1} \sin 2 \beta_{2}-k^{2} \cos ^{2} 2 \beta_{2}}{\sin 2 \alpha_{1} \sin 2 \beta_{2}+k^{2} \cos ^{2} 2 \beta_{2}} \\
\frac{A_{3}}{A_{1}}=-\frac{2 k \sin 2 \alpha_{1} \cos 2 \beta_{2}}{\sin 2 \alpha_{1} \sin 2 \beta_{2}+k^{2} \cos ^{2} 2 \beta_{2}}
\end{array}\right.
$$

where $k=\frac{C_{p}}{C_{s}}$.

For normal incidence, it can be obtained that $A_{3}=0$ and $A_{1}=A_{2}$ from equations (12) and (13). In this case, the incident $\mathrm{P}$-wave is reflected as a $\mathrm{P}$-wave. The amplitude of the reflected $\mathrm{P}$-wave is the same with the incident $\mathrm{P}$-wave and its phase changes $\pi$. The incident compressive wave becomes a tensile wave.

\subsubsection{Reflection of S-waves at the Free Surface}

Assume a S-wave incident on the free surface with an incident angle of $\beta_{1}^{\prime}$, which propagates in the $O x_{1} x_{2}$ plane. Different from P-waves, the polarization of S-wave must be specified. Because an arbitrary displacement can be polarized to two components perpendicular to each other, the S-wave is polarized parallel to the $O x_{1} x_{2}$ plane known as $\mathrm{SV}$-wave and perpendicular to the $O x_{1} x_{2}$ plane known as SH-wave.

For a SV-wave, the displacements $u_{3}=0$ and $u_{1}$ and $u_{2}$ refer to $x_{1}, x_{2}$ and $t$. So the problem is a plane motion problem. The solution method is similar as the case of the incident P-wave. The incident angle of SV-wave is $\beta_{1}^{\prime}$, and the boundary conditions at $x_{1}=0$ are $\sigma_{11}=0$ and $\sigma_{12}=0$, as shown in Fig. (2). 


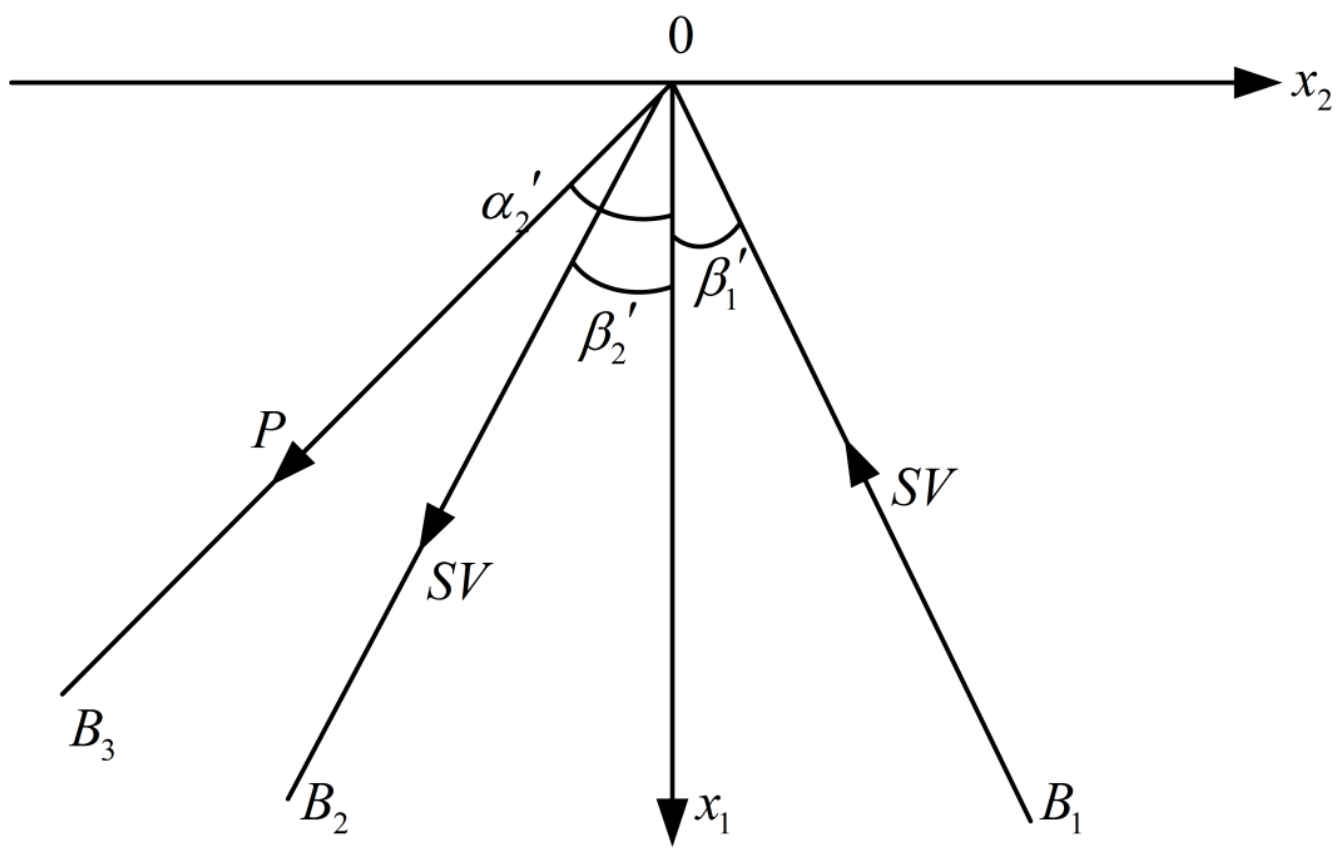

Fig. (2). Reflection of S-waves at the free surface.

The boundary conditions can be satisfied only when both reflected P-waves and SV-waves are excited. The reflection angle of reflected SV-wave equals to the incident angle, i.e. $\beta_{2}{ }^{\prime}=\beta_{1}{ }^{\prime}$. The reflection angle of reflected P-wave is obtained from the equation $\frac{\sin \alpha_{2}^{\prime}}{\sin \beta^{\prime}}=\frac{C_{p}}{C_{s}}$. Obviously $\alpha_{2}^{\prime}>\beta_{1}^{\prime}$. The amplitude of incident SV-wave is $B_{1}$, the amplitude of reflected SV-wave is $B_{2}$ and the amplitude of reflected P-wave is $B_{3}$.

Then the boundary conditions at $x_{1}=0$ can be written as follows,

$$
\left\{\begin{array}{l}
\left(B_{1}-B_{2}\right) \cos \beta_{1}{ }^{\prime}+B_{3} \sin \alpha_{2}{ }^{\prime}=0 \\
\left(B_{1}+B_{2}\right) \sin \beta_{1}{ }^{\prime}+B_{3} \cos \alpha_{2}{ }^{\prime}=0
\end{array}\right.
$$

For a given incident $\mathrm{SV}$-wave, the amplitudes of reflected waves $B_{2}$ and $B_{3}$ can be obtained as follows,

$$
\left\{\begin{array}{l}
\frac{B_{2}}{B_{1}}=\frac{\sin 2 \alpha_{2}^{\prime} \sin 2 \beta_{1}^{\prime}-k^{2} \cos ^{2} 2 \beta_{1}^{\prime}}{\sin 2 \alpha_{2}^{\prime} \sin 2 \beta_{1}^{\prime}+k^{2} \cos ^{2} 2 \beta_{1}^{\prime}} \\
\frac{B_{3}}{B_{1}}=\frac{-2 k^{2} \sin 2 \beta_{1}^{\prime} \cos 2 \beta_{1}^{\prime}}{\sin 2 \alpha_{2}^{\prime} \sin 2 \beta_{1}^{\prime}+k^{2} \cos ^{2} 2 \beta_{1}^{\prime}}
\end{array}\right.
$$

For SH-waves, whose propagating direction is perpendicular to the $O x_{1} x_{2}$ plane, no movement is caused in $x_{1}$ and $x_{2}$ directions, i.e. $u_{1}=0$ and $u_{2}=0$. When a SH-wave is incident on the free surface, it can be found form boundary conditions that only a reflected SH-wave is produced. The reflection angle equals to the incident angle. The reflected $\mathrm{SH}$-wave has the same amplitude and the opposite phase with the incident $\mathrm{SH}$-wave.

\subsubsection{Mathematical Models for Blasting Vibration Safety Criteria}

Based on stress wave theory, wave speed is closely related to the density, elastic modulus and Poisson's ratio [14], the wave speeds of P-waves and SV-waves are given by: 


$$
\left\{\begin{array}{c}
C_{p}=\sqrt{\frac{E_{d}(1-v)}{\rho(1+v)(1-2 v)}} \\
C_{s}=\sqrt{\frac{E_{d}}{2 \rho(1+v)}}
\end{array}\right.
$$

where $C_{p}$ is the wave speed of P-waves, $C_{s}$ is the wave speed of S-waves, $E_{d}$ is the dynamic modulus, $\rho$ is density, $v$ is the Poisson's ratio.

By analyzing the propagation of blasting stress wave in rock mass and the stress state of rock mass under blasting impacts, the formulas of dynamic stress at wave fronts are given by [15]:

$$
\left\{\begin{array}{c}
\sigma_{p i}=C_{p} \rho V_{p} \\
\tau_{s i}=C_{s} \rho V_{s}
\end{array}\right.
$$

where $\sigma_{p i}$ is the normal stress induced by the incident $\mathrm{P}$-wave, $\tau_{s i}$ is the shear stress induced by the incident $\mathrm{S}$-wave, $V_{p}$ is the vibration velocity induced by the incident $\mathrm{P}$-wave, $V_{s}$ is the vibration velocity induced by the incident S-wave.

According to the ultimate tensile stress criterion, if the incident angle of stress waves (P-waves, $\mathrm{S}$-waves) is $\theta$, then:

$$
\left[\sigma_{t}\right]=\sigma_{P r} \cdot \cos \theta
$$

where $\left[\sigma_{t}\right]$ is the ultimate tensile strength, $\sigma_{P r}$ is the tensile stress induced by reflected P-waves.

If a P-wave reflects on the free surface, $\theta=\alpha_{1}$ according to the definition of incident angle in Chapter 2.1. By substituting equations (14), (17) and (18) to equation (19), the blasting vibration safety criteria of P-waves is given by:

$$
V_{P}(\sigma)=\frac{\left[\sigma_{t}\right] \cdot\left(2 \cos \alpha_{1} \sin ^{2} \beta_{2} \sin 2 \beta_{2}+\cos ^{4} \beta_{2} \sin \alpha_{1}\right)}{2 \cos ^{2} \alpha_{1} \sin ^{2} \beta_{2} \sin 2 \beta_{2}-\cos ^{4} \beta_{2} \sin \alpha_{1} \cos \alpha_{1}} \cdot \sqrt{\frac{(1+v)(1-2 v)}{E_{d}(1-v) \cdot \rho}}
$$

If a S-wave reflects on the free surface, $\theta=\beta_{1}^{\prime}$ according to the definition of incident angle in Chapter 2.2. By substituting equations (16), (17) and (18) to equation (19), the blasting vibration safety criteria of P-waves is given by:

$$
V_{S}(\sigma)=\frac{\left[\sigma_{t}\right] \cdot\left(\sin 2 \alpha_{2}^{\prime} \sin 2 \beta_{1}^{\prime}+k^{2} \cos ^{2} 2 \beta_{1}^{\prime}\right)}{-2 k^{2} \sin 2 \beta_{1}^{\prime} \cos 2 \beta_{1}^{\prime} \cos \beta_{1}^{\prime}} \cdot \sqrt{\frac{2(1+v)}{E_{d} \cdot \rho}}
$$

\subsection{Ultimate Strength of Slope Surficial Rocks}

Numerous studies and engineering practices prove that the failure characteristics of rock mass under static and dynamic loads are of a huge difference. Different rocks and different stress states result in different failure modes, but the main failure mode can be found. For hard brittle rocks (such as marble and diorite), shear failure or tensile failure dominates the failure modes, and the envelope is approximate a straight line [16]. But under blasting-vibration-induced dynamic loads, shear failure is rarely found in such rock materials, and tensile failure.

The strength of rock mass under blasting-vibration-induced dynamic loads will increase to some certain extent, the increasing of ultimate tensile strength and elastic modulus is dependent to loading rate. The relation between static tensile strength and dynamic tensile strength is given by [17]:

$$
\left[\sigma_{t}\right]=\sigma_{t 0}\left[1+0.12 \lg \left(V_{H}\right)\right]=\overline{K_{D T}} \sigma_{t 0}
$$

where $\left[\sigma_{t}\right]$-dynamic tensile strength;

$\sigma_{t}-$ static tensile strength;

$V_{H}$-loading rate, $V_{H}=\sigma_{H} / \sigma_{1}$; 
$\sigma_{H}$-arbitrary loading $\operatorname{speed}\left(\sigma_{H} \geq 1\right)$;

$\sigma_{1}$-loading speed, $\sigma_{1}=0.1 \mathrm{Mpa} / \mathrm{s}$;

$\overline{K_{D T}}$-increasing factor for tensile strength.

Similarly, the relation between static elastic modulus and dynamic elastic modulus is given by [18]:

$$
E_{\mathrm{d}}=E_{\mathrm{d} 0}\left[0.02 \lg \left(V_{H}\right)^{2}+0.15 \lg \left(V_{H}\right)+1\right]=\overline{K_{D E}} E_{\mathrm{d} 0}
$$

where $E_{d}$-dynamic elastic modulus;

$E_{d}$ - static elastic modulus;

$\overline{K_{D E}}$-increasing factor for elastic modulus.

The loading speed of blasting seismic waves is up to $10^{6} \mathrm{MPa} / \mathrm{s}$ and in general, the sensitive loading speed of slopes and underground structures is $10 \sim 10^{3} \mathrm{MPa} / \mathrm{s}$ [17]. So, when the $\sigma_{H}$ is $10 \sim 10^{3} \mathrm{MPa} / \mathrm{s}$, it can be calculated that from equations (22) and (23):

$$
\overline{K_{D T}} \in(1.24,1.48), \overline{K_{D E}} \in(1.38,1.92)
$$

The average values of the increasing factor for tensile strength and the increasing factor for elastic modulus are $\overline{K_{D T}}$ $=1.36, \overline{K_{D E}}=1.65$ respectively.

\section{RESULTS AND DISCUSSIONS}

\subsection{Field Conditions of Open-pit to Underground Mining in Daye Iron Mine}

Daye Iron Mine is located in Tieshan District, Huangshi City, Hubei Province, PR China, about 90km west to Wuhan City, $25 \mathrm{~km}$ east to the downtown of Huangshi City, $15 \mathrm{~km}$ southeast to Daye City, as shown in Fig. (3). A deep open pit has been formed throughout 100 years of mining activities, which is $2400 \mathrm{~m} \mathrm{E-W}$ and $1000 \mathrm{~m} \mathrm{~N}-\mathrm{S}$. The east open pit of Daye Iron Mine was selected as the study area, as shown in Fig. (4). The north slope is $170 \mathrm{~m}-270 \mathrm{~m}$ above mean sea level (ASL), and the south slope is $86 \mathrm{~m}-200 \mathrm{~m}$ ASL. The overall slope angle varies from $38^{\circ}$ to $43^{\circ}$, and some inter-ramp angles are up to $53^{\circ}$. It is a precursory and typical open-pit to underground mine in China. Marble mainly distributes in the south slope and diorite mainly distributes in the north slope. In open-pit mining, the bench height is $12 \mathrm{~m}$ and the bottom elevation is $-48 \mathrm{~m}$ ASL. In order to ensure the slope stability, the bottom has backfilled up to $\pm 0 \mathrm{~m}$ ASL. In underground mining, sublevel caving method is adopted. The current mining operations are at $-84 \mathrm{~m}$ ASL, and the occurrence of ores is deep to $-168 \mathrm{~m}$ ASL.

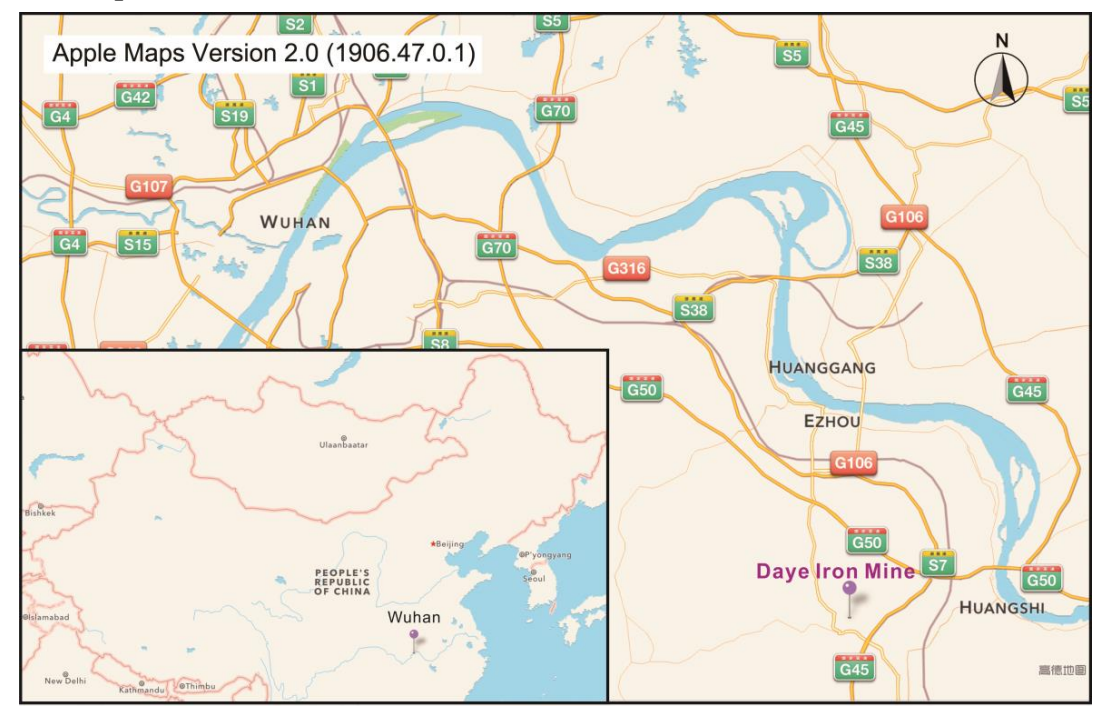

Fig. (3). Location of Daye Iron Mine in Hubei Province, China. 


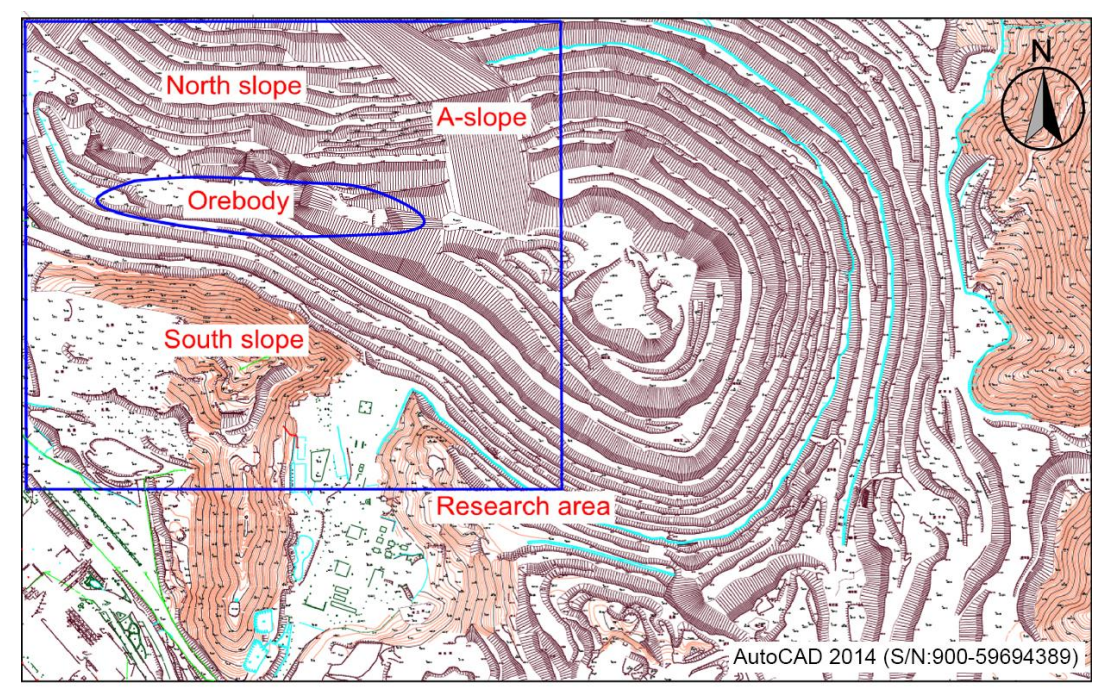

Fig. (4). Top view of east open pit in Daye Iron Mine.

The static mechanical parameters of the rock mass in open-pit slopes of Daye Iron Mine are obtained by compression tests and tensile strength tests. The rock samples were processed into cylinder with diameter of $50 \mathrm{~mm}$ and height of $100 \mathrm{~mm}$, and part of samples are showing in Fig. (5), and compression tests of rock sample are showing in Fig. (6). The details of laboratory tests of mechanical parameters of the rock samples are described in Zhang's research [19]. With equation (24) taken into consideration, the dynamic mechanical parameters are calculated, as listed in Table 1.

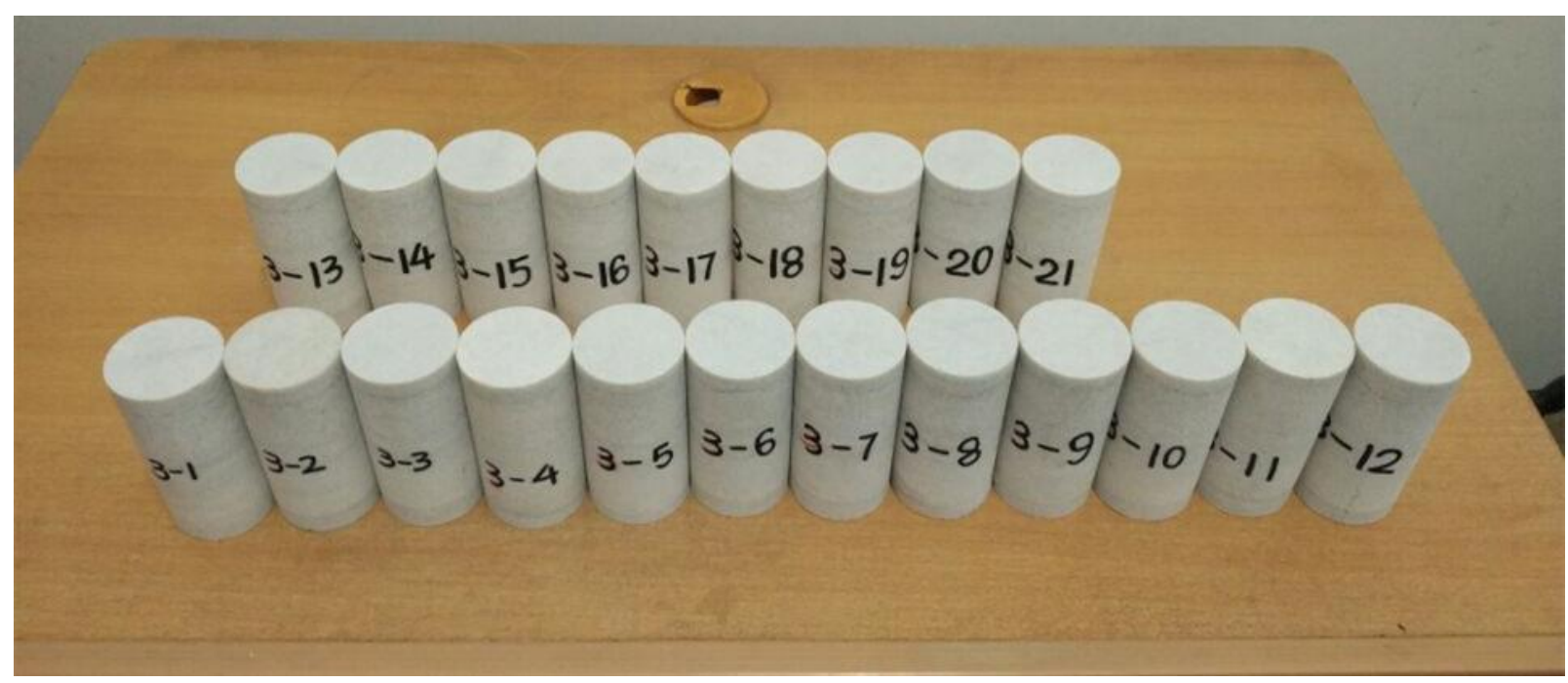

Fig. (5). Part of marble samples.

Table 1. Parameters of rock mass of open-pit slopes.

\begin{tabular}{|c|c|c|c|c|}
\hline Parameters & Symbol & Units & Marble & Diorite \\
\hline Static elastic modulus & $E_{d 0}$ & $\mathrm{GPa}$ & 16.22 & 18.37 \\
\hline Static tensile strength & $\sigma_{t 0}$ & $\mathrm{GPa}$ & 12.11 & 13.82 \\
\hline Dynamic elastic modulus & $E_{d}$ & $\mathrm{GPa}$ & 26.76 & 30.31 \\
\hline Dynamic tensile strength & $\sigma_{t}$ & $\mathrm{GPa}$ & 16.47 & 18.80 \\
\hline Density & $\rho$ & $\mathrm{kg} / \mathrm{m}^{3}$ & 2710 & 2830 \\
\hline Poisson's ratio & $v$ & $/$ & 0.23 & 0.23 \\
\hline
\end{tabular}




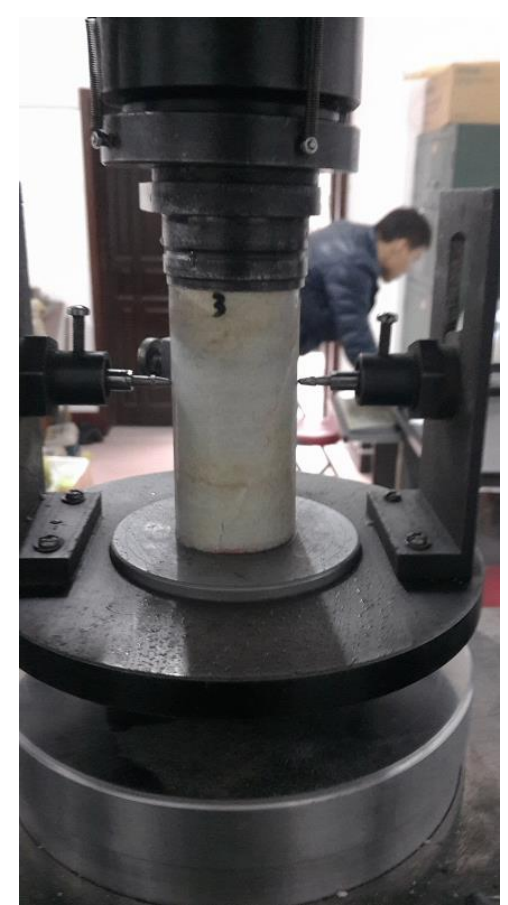

Fig. (6). Photo of compression tests of rock sample.

\subsection{Theoretical Analysis of Blasting Vibration Safety Criteria}

According to the field conditions, a section along the center of underground stope is selected and simplified to determine the range of incident angles when blasting stress waves propagate to slope surfaces, as shown in Fig. (7). Benches on south and north slopes are neglected. The overall slope angle of the north slope is $45^{\circ}$ and the slope height is $245 \mathrm{~m}$; the overall slope angle of the south slope is $39^{\circ}$ and the slope height is $128 \mathrm{~m}$. The current mining operations are at $-84 \mathrm{~m}$ ASL, and the occurrence of ores is deep to $-168 \mathrm{~m}$ ASL.

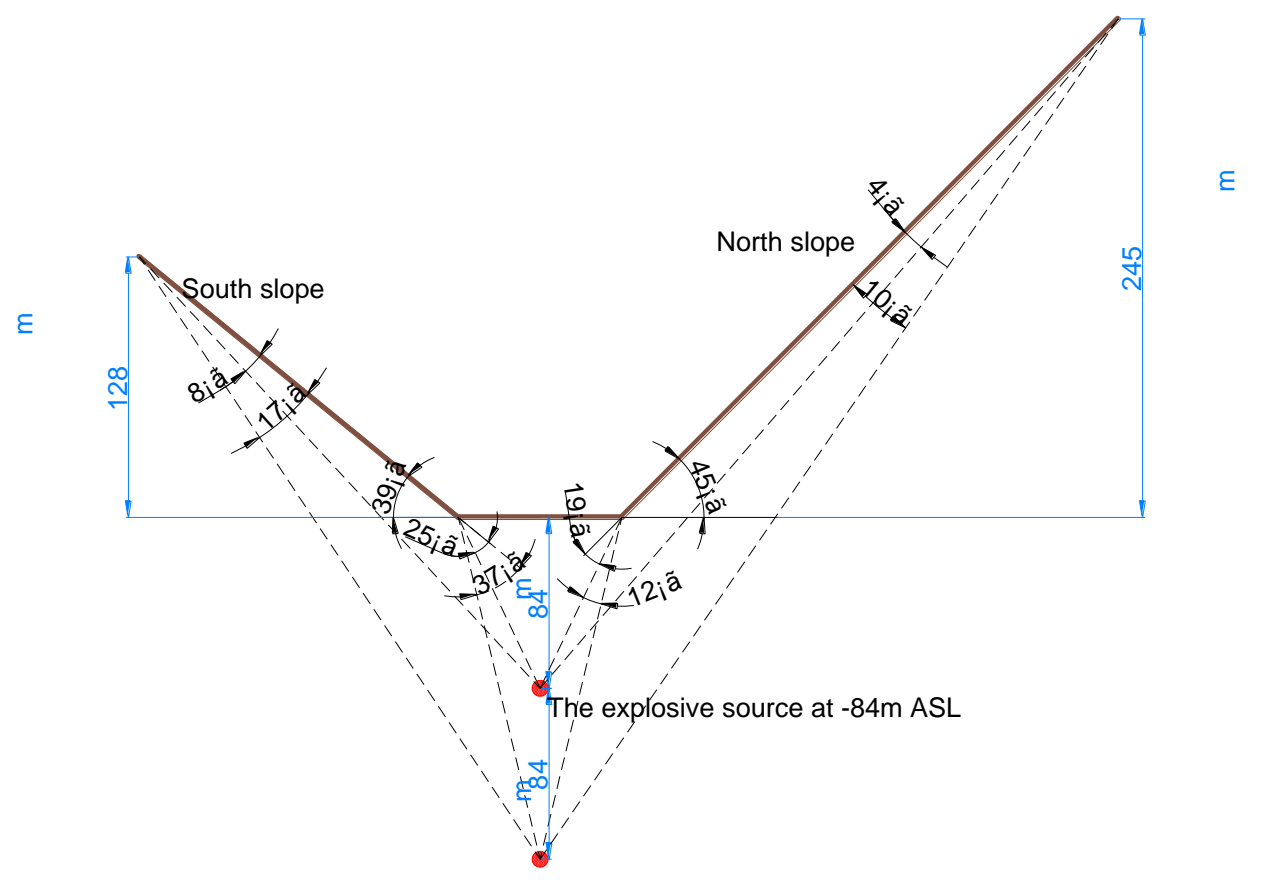

Fig. (7). Range of incident angles in the mine.

It can be obtained from Fig. (7) that for north slopes, the range of incident angle is from $71^{\circ}$ to $86^{\circ}$ and for south slopes, the range of incident angle is from $51^{\circ}$ to $82^{\circ}$. 
In order to ensure the stability of mine slopes, the influence of underground mining blasting operations should be modified according to its importance and potential damage. Because the mine slopes in Daye iron mine are permanent, it will seriously threaten the workers and underground stopes once rockfalls, collapses and even landslides occur. So the modification factor of 1.7 is chosen according to the Specifications of Earthquake Resistant Design for Highway Engineering in China [20].

According to the parameters listed in Table 1, the blasting vibration safety criteria can be calculated from equations (20) and (21), as follows:

$$
\left\{\begin{array}{l}
V_{\text {North }}(\sigma) \in(11.08 \mathrm{~cm} / \mathrm{s}, 50.26 \mathrm{~cm} / \mathrm{s}) \\
V_{\text {South }}(\sigma) \in(10.20 \mathrm{~cm} / \mathrm{s}, 47.89 \mathrm{~cm} / \mathrm{s})
\end{array}\right.
$$

According to the relevant research achievements, the frequency of incident stress waves has little influence on rock strength [21]. According to equation (25), in order to ensure the safety of the slope is absolute, the blasting vibration safety criteria for north slope and south slope can be proposed to $11.08 \mathrm{~cm} / \mathrm{s}$ and $10.20 \mathrm{~cm} / \mathrm{s}$ respectively.

According to the Safety Regulations for Blasting in China [22], the blasting vibration safety criteria for permanent rock slopes is $5 \mathrm{~cm} / \mathrm{s}$ to $15 \mathrm{~cm} / \mathrm{s}$. The rock-strength-based blasting vibration safety criteria in this paper agree well with it, but are more accurate and rational. The criteria proposed in this paper will play a significant role in underground mining blasting operations and preventing from rockfalls.

\section{CONCLUSION}

1. The influence of stress wave on surficial rock mass was analyzed when stress waves travel to the slope surface, and a mathematical model for blasting vibration safety criteria is proposed based on the ultimate tensile stress criterion, ultimate shear stress criterion and Mohr-Coulomb criterion.

2. In order to ensure the stability of mine slopes, the influence of underground mining blasting operations should be modified according to its importance and potential damage.

3. According to the field conditions, the blasting vibration safety criteria for the north slope and south slope in Daye iron mine are $11.08 \mathrm{~cm} / \mathrm{s}$ and $10.20 \mathrm{~cm} / \mathrm{s}$ respectively, which accords with the Safety Regulations for Blasting in China, and is more accurate and rational. The results provide a scientific reference for the relevant specifications.

\section{CONFLICT OF INTEREST}

The authors declare no conflict of interest, financial or otherwise.

\section{ACKNOWLEDGEMENTS}

The study was sponsored by the National Natural Science Foundation of China (Grant No.41372312 and No.51379194), the Fundamental Research Funds for the Central Universities of China University of Geosciences (Wuhan) (Grant No. CUGL140817), the Natural Science Foundation of Hubei Province of China (Grant No. 2014CFB894) and the China Postdoctoral Science Foundation (Grant No. 2014M552113).

\section{REFERENCES}

[1] B.-H. Choi, C.-H. Ryu, D. Deb, Y.-B. Jung, and J.-H. Jeong, "Case study of establishing a safe blasting criterion for the pit slopes of an openpit coal mine", Int. J. Rock Mech. Min. Sci., no. 57, pp. 1-10, 2013. [http://dx.doi.org/10.1016/j.ijrmms.2012.07.014]

[2] T.B. Afeni, and S.K. Osasan, "Assessment of noise and ground vibration induced during blasting operations in an open pit mine: A case study on Ewekoro limestone quarry, Nigeria", Min. Sci. Technol. (China), vol. 19, no. 4, pp. 420-424, 2009. [http://dx.doi.org/10.1016/S1674-5264(09)60078-8]

[3] D. Deb, K. Kaushik, B. Choi, C. Ryu, Y. Jung, and C. Sunwoo, "Stability assessment of a pit slope under blast loading: a case study of Pasir coal mine", Geotech. Geol. Eng., vol. 29, no. 4, pp. 419-429, 2011. [http://dx.doi.org/10.1007/s10706-010-9387-4]

[4] Y. Hu, W. Lu, M. Chen, P. Yan, and J. Yang, "Comparison of blast-induced damage between presplit and smooth blasting of high rock slope", Rock Mech. Rock Eng., vol. 47, no. 4, pp. 1307-1320, 2014. [http://dx.doi.org/10.1007/s00603-013-0475-7] 
[5] M. Saadat, M. Khandelwal, and M. Monjezi, "An ANN-based approach to predict blast-induced ground vibration of Gol-E-Gohar iron ore mine, Iran", J. Rock Mech. Geotech. Eng., vol. 6, no. 1, pp. 67-76, 2014. [http://dx.doi.org/10.1016/j.jrmge.2013.11.001]

[6] A. Kesimal, B. Ercikdi, and F. Cihangir, "Environmental impacts of blast-induced acceleration on slope instability at a limestone quarry", Environ. Geol., vol. 54, no. 2, pp. 381-389, 2008. [http://dx.doi.org/10.1007/s00254-007-0825-4]

[7] Y. Yu-jiang, L. Yan, and L. Jian-po, "Dynamic stability of open pit slope under blast loading", J. Northeastern Univ., vol. 32, no. 10, pp. 1472-1475, 2011. [Natural Science].

[8] Y. Yan, Y. Zhang, and C. Huang, "Impact of blasting vibration on soil slope stability", Electron. J. Geotech. Eng., vol. 19, pp. 6559-6568, 2014.

[9] Y. -q, YANG. J., YU, and D. -Y, "Study on simulation of discontinuous deformation analysis for slope stability under blast impact", Acta Armamentarii, vol. 74-78, no. S1, 2010.

[10] LI. N, Zhang. X, and Yu. C, "Research on dynamic response of prestressed anchorcables subjected to blasting load on slope", Chinese J. Rock Mech. Eng. vol. 26, suppl. 1, pp. 2593-2600, 2007.

[11] H.R. Azizabadi, H. Mansouri, and O. Fouché, "Coupling of two methods, waveform superposition and numerical, to model blast vibration effect on slope stability in jointed rock masses", Comput. Geotech., vol. 61, pp. 42-49, 2014. [http://dx.doi.org/10.1016/j.compgeo.2014.04.008]

[12] H. Xu, "Study on the dynamic stability of high rock slope induced by blasting vibration", Ph.D. thesis, Wuhan University, Wuhan, Heibei, China, 2006.

[13] Achenbach J., Wave propagation in elastic solids., vol. 16, Elsevier: Holland, 2012.

[14] J. Miklowitz, The theory of elastic waves and waveguides., Elsevier: Holland, 2012.

[15] Y. Yu, Engineering blasting theory and technology., Metallurgy Industry Press: Beijing, 2004.

[16] Y. Li, X. Ge, C. Mi, and H. Zhang, "Failure criteria of rock-soil-concrete and estimation of their strength parameters", Chinese J. Rock Mec. Eng., vol. 23, no. 5, pp. 770-776, 2004.

[17] C. Zhang, "Analysis of vibration velocity maximum of the lining of existing tunnel by the blasting of the tunnel near-by", M.S. thesis, Lanzhou Jiaotong University, Lanzhou, Gansu, China, 2009.

[18] L. Jianhua, L. Zhang, and Y. Ronggui, "Mechanism of rock slope unstability and critical vibration velocity under action of blasting seism wave", Min. Metall., vol. 10, no. 1, pp. 11-15, 2001.

[19] Z. Zhang, "Study on the Influence Mechanism of Stability of Super High-steep Slope in Underground Mining by Caving Method", M.S. thesis, China University of Geosciences, Wuhan, Hubei, China, 2012.

[20] TB10003-2005, C.C.C.C.: Specification for railway tunnel design In., China Railway Press: Beijing, 2005.

[21] C. Ming, L. Wenbo, and W. Liang, "Safety threshold of blasting vibration velocity to high rock slope of Xiaowan hydropower station", Chinese J. Rock Mec. Eng., vol. 26, no. 1, pp. 51-56, 2007.

[22] GB6722-2011, C.S.o.E.a.B.: Safety Regulations for Blasting. In. China Standard Press, Beijing, 2011.

(C) 2017 Jiang et al.

This is an open access article distributed under the terms of the Creative Commons Attribution 4.0 International Public License (CC-BY 4.0), a copy of which is available at: https://creativecommons.org/licenses/by/4.0/legalcode. This license permits unrestricted use, distribution, and reproduction in any medium, provided the original author and source are credited. 